\title{
The magnitude of anemia and associated factors among pregnant women attending public institutions of Shire Town, Shire, Tigray, Northern Ethiopia, 2018
}

\author{
Awoke Kebede ${ }^{1 *}$, Hadgu Gerensea ${ }^{1}$, Freweyni Amare ${ }^{1}$, Yared Tesfay ${ }^{2}$ and Girmay Teklay ${ }^{1}$
}

\begin{abstract}
Objective: Anemia is a widespread health problem among pregnant women causing maternal/infant morbidity and mortality mainly in low-income countries. Understanding of the magnitude of anemia and related socio-demographic variables in a specific setting would help scale-up preventive and therapeutic measures in a locality. So that this study focuses on the magnitude of anemia and its associated factor among pregnant women attending antenatal care in public hospitals of shire town and using institution based cross-sectional study design on 480 randomly selected study subjects.

Result: The overall prevalence of anemia was 16.3\%. Majority of the participants (52\%) have mild anemia (10$10.9 \mathrm{gm} / \mathrm{dl}$ ). Pregnant mothers with human immunodeficiency virus, intestinal parasitic infection and having lower inter-pregnancy gap were significant predictors of anemia. Preventing infection of the mother during pregnancy and making the gap between pregnancies are necessary.
\end{abstract}

Keywords: Pregnant women, Anemia, Micronutrient deficiency

\section{Introduction}

Anemia is a condition in which the number or size of red blood cells and thus hemoglobin (Hgb) concentration fall below the required level resulting in the impaired capacity to transport oxygen [1]. Anemia is a major global public health concern. The highest proportions of peoples affected are from sub-Saharan Africa and Southeast Asia. It affects all ages- and sex-groups with the highest prevalence, $43 \%, 38 \%$, occurring among less than 5 years children and pregnant women respectively [1].

Anemia in pregnancy is defined based on the level of pregnancy. For first and third trimesters Hgb levels $<11 \mathrm{~g} / \mathrm{dl}$ and for second trimester $<10.5 \mathrm{~g} / \mathrm{dl}$ are considered anemic [2]. It was estimated that anemia may be responsible for as much as $20 \%$ of all maternal deaths

\footnotetext{
*Correspondence: honeyfikir1@gmail.com

1 School of Nursing, College of Health Sciences and Comprehensive Specialized Hospital, Aksum University, Aksum, Ethiopia

Full list of author information is available at the end of the article
}

in sub-Saharan Africa through three main mechanisms [3]. And Ethiopian Demographic Health Survey (EDHS) report, $17 \%$ of reproductive age women were estimated to be anemic and $22 \%$ of the pregnant women are anemic [4].

Therefore the aim of this study was to determine the magnitude of anemia and associated factor among pregnant women attending the antenatal clinic in public health in shire town.

\section{Main text \\ Study area}

The study was done in Shire town northwestern zone which was located in north part of Ethiopia $1087 \mathrm{~km}$ from Addis Ababa, and $300 \mathrm{~km}$ from Mekelle city, the Capital of Tigray with a total population of 47,284 (21,867 male and 25,417 female). Based on the 2007 national census conducted by the central statistical agency, this town has total population of 47,284 , of whom 21,867 are men 
and 25,417 women. Majority of the inhabitants $(85.11 \%)$ follow Ethiopian Orthodox Christianity but $14.67 \%$ are Muslims. The Suhul hospital found in shire town is estimated to serve more than one million people residing in the town and neighboring areas [5-12]. The study was conducted from April 1-30, 2018.

\section{Study design}

The institutional based cross-sectional study design was conducted.

\section{Sample size}

A total of 313 samples were calculated using a single population proportion formula by assuming $5 \%$ marginal error and $95 \%$ confidence interval $(\sigma=0.05)$ and prevalence of anemia $27.4 \%$ [13] and by adding $10 \%$ of nonresponse rate.

\section{Sampling technique}

From all health facilities in the study area, one hospital and two health centers were selected. Random sampling method was used to select participants from women attending antenatal care follow-up.

\section{Data collection tool}

A structured questionnaire was adopted and adapted from review of relevant literature and arranged according to particular objective it can address. Before actual data collection, the tool was pre-tested in St. Mary Hospital. Three days of training was given to all data collectors and supervisors prior to pretesting. Eight data collectors who had completed a degree in midwives were recruited. The data was collected through self-administer questionnaire.

\section{Variables}

Dependent variable: Magnitude of anemia

Independent variables: Age, education, gravida/parity, gestational age, medical/surgical problems (intestinal parasite, HIV, malaria, malnutrition)

\section{Data processing and analysis}

Data were entered and analyzed using SPSS version 22.0. Descriptive statistics were employed to calculate frequencies and display findings. Association was measured using binary logistic regression. Based on Bivariate analysis variables that showed significant association at $(p<0.25)$ were entered into the multivariable analysis to select Predictor variables of factors affecting anemia in pregnant women. The final model were then tested for its goodness of fit by Hosmer and Lemeshow p-value and $p$-value $>0.05$ was the best fitted. Finally, variables that showed significant associations at $(\mathrm{p}<0.05)$ were identified as independent predictors of affecting anemia in pregnant women.

\section{Ethical considerations}

The Ethical approval was approved by the Institutional Review Board (IRB) of the College of Health Sciences, Aksum University. Communications with the health center administrations were made through a formal letter obtained from Aksum University, College of Health Science and TRHB. The objective and importance of the study were explained to the study participants. Data was collected after full informed written consent was obtained from participants aged 18 years and more, but age less than 18 years from the guardian. Confidentiality of the information was maintained throughout by excluding names as identification in the questionnaire and keeping their privacy during the interview by interviewing them alone.

\section{Results}

\section{Socio-demographic data}

A total of 480 pregnant women aged 18-38 years (mean age 28.2) were examined during the study period. The majority $(73.3 \%)$ of the women were within the age group $25-31$. The majority $(89.0 \%)$ of the participants were married. More than half of the participants (52.2\%) were unemployed. The medical history of the participants showed that 35 (7.3\%) had clinical malaria within past 1 year, 35 (7.3\%) intestinal parasitic infections (IPIs) and $31(6.5 \%)$ reactive to HIV antibody test. Although the majority of the participants $343(71.5 \%)$ had a normal body mass index, there were $71(14.8 \%)$ underweight and $66(13.8 \%)$ overweight individuals. While 25 (5.2\%) of the participants were self-reported alcohol consumers, slightly more 31 (6.5\%) were smokers. All the women answered that they had no history of recent bloody diarrhea or bleeding, chronic kidney or other infectious or non-infectious diseases (see Table 1).

Regarding trimester, most participants $(41.3 \%)$ the current pregnancy was their first (primigravida) and for 155 (32.3\%) it was their fourth or above (multi-gravida), $127(26.5 \%)$ were experiencing their second or third pregnancy. Most of the participants 189 (39.9\%) were in their first trimester followed by those in their third 167 $(34.8 \%)$ and in their second 124 (25.8\%). Regarding the inter-pregnancy gap, for those who have more than one pregnancy, 32 (12.1\%) had below 2, 143 (50.7\%) 2-3 and 105 (37.2\%) had more than 3 years of gaps between their successive pregnancies.

The overall prevalence of anemia $(\mathrm{Hgb}<11.0 \mathrm{~g} / \mathrm{dl})$ among the pregnant women was $16.3 \%$ with $48 \%$ moderate and 52\% mild cases none being severe. The mean $\mathrm{Hgb}$ was $12 \mathrm{~g} / \mathrm{dl}$ with the lowest and highest values 7.8 and 
Table 1 Socio-demographic characteristic and behaviors of pregnant mothers attending ANC in public institutions of Shire Town, Tigray, Northern Ethiopia, 20,168 $(\mathrm{N}=480)$

\begin{tabular}{lll}
\hline Variable & Anemia status & Total no. (\%) \\
\cline { 2 - 3 } Anemic, no. (\%) & $\begin{array}{l}\text { Non-anemic, no. } \\
(\%)\end{array}$
\end{tabular}

\begin{tabular}{lrrc}
\hline Age in year & & & \\
$18-24$ & $6(22.2)$ & $21(77.8)$ & $90(5.6)$ \\
$25-32$ & $57(16.1)$ & $295(83.9)$ & $352(73.3)$ \\
$32-38$ & $15(14.9)$ & $86(85.1)$ & $101(21.0)$ \\
Marital status & & & \\
Single & $6(11.3)$ & $47(88.7)$ & $53(11.0)$ \\
Married & $72(16.9)$ & $355(85.1)$ & $427(89.0)$ \\
Employment & & & \\
Employed & $30(13.2)$ & $198(86.8)$ & $228(47.5)$ \\
Unemployed & $48(19.1)$ & $204(80.9)$ & $521(52.5)$ \\
Malaria during pregnancy & & $35(7.3)$ \\
Yes & $11(31.4)$ & $24(68.6)$ & $445(92.7)$ \\
No & $67(15.1)$ & $378(84.9)$ & $35(7.3)$ \\
Intestinal parasite & & $445(92.7)$ \\
Yes & $13(37.1)$ & $22(62.9)$ & \\
No & $65(14.6)$ & $380(85.4)$ & $31(6.5)$ \\
HIV status & & & $449(93.5)$ \\
Positive & $12(38.7)$ & $19(61.3)$ & $31(6.5)$ \\
Negative & $66(14.7)$ & $383(85.3)$ & $449(93.5)$ \\
Smoking & & & \\
Yes & $9(29.0)$ & $22(71.0)$ & $(94.5)$ \\
No & $69(15.4)$ & $380(84.6)$ & \\
Alcohol consumption & & \\
Yes & $10(40.0)$ & $15(60.0)$ & \\
No & $68(14.9)$ & $387(86.1)$ & \\
\hline
\end{tabular}

$13.8 \mathrm{~g} / \mathrm{dl}$ respectively. The mean hematocrit was $33.7 \%$. The prevalence of anemia was high among pregnant women who were IPIs-positive (37.1\%), HIV-seropositive $(38.7 \%)$ and mothers with more than three pregnancies (32.3\%) and prevalence of anemia increased as the number of pregnancy increased (see Table 2).

\section{Factors associated with anemia}

In multivariate analysis, participants who are positive for intestinal parasite were 3.46 times more likely to have anemia than those who were not (OR 3.46, 95\% CI 1.67-7.20, $\mathrm{p}=0.001$ ). Similarly, HIV-positivity was a statistically significant predictor of anemia (OR 3.67, 95\% CI 1.70-7.90, $\mathrm{p}=0.001$ ). Individuals who had less than 2 years inter pregnancy gap were also at significantly higher risk of having anemia than those who had 2-3 years gaps (OR 7.312, 95\% CI 3.041-17.587, $\mathrm{p}=0.001)$. Finally, all the above three variables positive for an intestinal parasite, HIV positive and narrow inter
Table 2 Pregnancy-related conditions of anemia in pregnant mothers attending ANC in public institutions of Shire Town, Tigray, Northern Ethiopia, 20,168 ( $N=480)$

\begin{tabular}{|c|c|c|c|}
\hline \multirow[t]{2}{*}{ Variable } & \multicolumn{2}{|l|}{ Anemia status } & \multirow[t]{2}{*}{ Total no. (\%) } \\
\hline & Anemic, no. (\%) & $\begin{array}{l}\text { Non-anemic, no. } \\
(\%)\end{array}$ & \\
\hline \multicolumn{4}{|l|}{ Trimester } \\
\hline First & $30(15.9)$ & $159(84.1)$ & $189(39.4)$ \\
\hline Second & $22(17.7)$ & $102(82.3)$ & $124(25.8)$ \\
\hline Third & $26(15.6)$ & $141(84.4)$ & $167(34.8)$ \\
\hline \multicolumn{4}{|c|}{ No. of pregnancy } \\
\hline 1 (current) & $24(12.1)$ & $174(87.9)$ & $198(41.3)$ \\
\hline $2-3$ & $18(14.2)$ & $109(85.8)$ & $127(26.5)$ \\
\hline$\geq 4$ & $36(23.2)$ & $119(76.8)$ & $155(32.3)$ \\
\hline \multicolumn{4}{|c|}{ Inter-pregnancy gap (years) } \\
\hline$<2$ & $6(14.7)$ & $29(85.3)$ & $34(12.1)$ \\
\hline $2-3$ & $22(15.4)$ & $121(84.6)$ & $143(50.7)$ \\
\hline$\geq 4$ & $14(13.3)$ & $91(86.8)$ & $105(37.2)$ \\
\hline \multicolumn{4}{|c|}{ Body mass index } \\
\hline Under weight & $19(19.7)$ & $57(80.3)$ & $71(14.8)$ \\
\hline Normal & $50(14.6)$ & $293(85.4)$ & $343(71.5)$ \\
\hline Overweight & 14 (21.2) & $52(78.8)$ & 66 (13.8) \\
\hline
\end{tabular}

pregnancy gap were found to be independently associated with the occurrence of anemia in the multivariate model (see Table 3).

\section{Discussion}

The overall anemia prevalence among the study participants was $16.3 \%$. This result is comparable with the results from Mekelle (16.6\%) and Gonder (19.3\%) respectively $[14,15]$. But this finding is lower than findings of Gilgel Gibe (53.9\%) and Gode South Ethiopia (565) [16, 17] and higher than in Iran (4.7\%) [18]. The variations may be explained by factors such as malaria endemicity particularly in Ghibe and Gode, study design and sample size, socio-economic and other baseline characteristics of the study populations as well as altitudinal differences. Further, early antenatal care follow-up and better healthcare awareness among the participants might have contributed towards the observed differences in anemia prevalence. Also, in countries like Iran iron and folate supplements are routinely prescribed for pregnant women and that might be among the reasons for the apparent very low prevalence rate in the country.

Positivity for intestinal parasite was significantly associated with anemia. The result of the study was consistent with the literature on possible factors of anemia in pregnancy in Shalla Woreda of Oromia region In Ethiopia 
Table 3 Factors associated with anemia in pregnant mothers attending ANC in public institutions of Shire Town, Tigray, Northern Ethiopia, 20,168 ( $=480)$

\begin{tabular}{|c|c|c|c|c|c|c|}
\hline \multirow[t]{2}{*}{ Variable } & \multicolumn{2}{|l|}{ Anemia status } & \multirow[t]{2}{*}{$\operatorname{COR}(95 \% \mathrm{Cl})$} & \multirow[t]{2}{*}{ p-value } & \multirow[t]{2}{*}{ AOR $(95 \% \mathrm{Cl})$} & \multirow[t]{2}{*}{ p-value } \\
\hline & Anemic, no. (\%) & Non-anemic, no. (\%) & & & & \\
\hline Age in year & & & & & - & \\
\hline $18-24$ & $6(22.2)$ & $21(77.8)$ & 3.24 (1.470-7.133) & 0.04 & & \\
\hline $25-32$ & $57(16.1)$ & $295(83.9)$ & $2.27(0.931-5.536)$ & 0.72 & & \\
\hline $32-38$ & $15(14.9)$ & $86(85.1)$ & 1.00 & & & \\
\hline Malaria during pregnancy & & & & & - & \\
\hline Yes & $11(31.4)$ & $24(68.6)$ & $2.58(1.210-5.526)$ & 0.14 & & \\
\hline No & $67(15.1)$ & $378(84.9)$ & 1.00 & & & \\
\hline \multicolumn{7}{|l|}{ HIV status } \\
\hline Positive & $12(38.7)$ & $19(61.3)$ & 3.67 (1.700-7.904) & 0.001 & $2.802(1.174-6.635)$ & 0.02 \\
\hline Negative & $66(14.7)$ & $383(85.3)$ & 1.00 & & & \\
\hline \multicolumn{7}{|l|}{ Intestinal parasite } \\
\hline Yes & $13(37.1)$ & $22(62.9)$ & $3.46(1.670-7.200)$ & 0.001 & $3.340(1.49-7.48)$ & 0.003 \\
\hline No & 65 (14.6) & $380(85.4)$ & 1.00 & & & \\
\hline Smoking & & & & & - & \\
\hline Yes & $9(29.0)$ & $22(71.0)$ & $2.25(1.995-5.090)$ & 0.05 & & \\
\hline No & $69(15.4)$ & $380(84.6)$ & 1.00 & & & \\
\hline Alcohol consumption & & & & & - & \\
\hline Yes & $10(40.0)$ & $15(60.0)$ & $2.79(1.637-6.794)$ & 0.06 & & \\
\hline No & $68(14.9)$ & $387(86.1)$ & 1.00 & & & \\
\hline No. of pregnancy & & & & & - & \\
\hline 1 (current) & $24(12.1)$ & $174(87.9)$ & $0.83(0.433-0.961)$ & 0.59 & & \\
\hline $2-3$ & $18(14.2)$ & $109(85.8)$ & $0.613(0.301-0.804)$ & 0.07 & & \\
\hline$\geq 4$ & $36(23.2)$ & $119(76.8)$ & 1.00 & & & \\
\hline \multicolumn{7}{|l|}{ Inter-pregnancy gap } \\
\hline$<2$ years & $6(14.7)$ & $29(85.3)$ & $7.31(3.041-17.587)$ & 0.001 & $6.665(2.69-16.483)$ & 0.001 \\
\hline $2-3$ years & $22(15.4)$ & $121(84.6)$ & $1.182(0.573-2.436)$ & 0.65 & & \\
\hline$\geq 4$ years & $14(13.3)$ & $91(86.8)$ & 1.00 & & & \\
\hline
\end{tabular}

$A O R$ adjusted odds ratio, $\mathrm{Cl}$ confidence interval, $C O R$ crude odds ratio, HIV human immunodeficiency virus

[19]. This is expected as intestinal parasites, apart from their competition for nutrients, are known to cause blood loss, loss of appetite reduced motility of food through the intestine and damage to the wall of the intestine leading to mal-absorption of nutrients.

The study also showed a significant association between anemia and HIV. Pregnant women with HIV was more likely to have anemia than those who without HIV in agreement with previous reports [20]. The high prevalence of anemia in HIV-positive pregnant women might be due to the characteristics of the virus which results in increased metabolic and nutritional needs; poor intake of iron and other nutrients due to reduced appetite, mal-absorption of nutrients; and direct suppression of red blood cell production in the body [21].
The study result showed the prevalence of anemia increased as the number of pregnancy increased. This is in similar with the finding of Wolita Sodo, South Ethiopia [22] in which number of pregnancy had a statistically significant association with anemia. This could be explained the body will have enough time to recover from a nutrient loss that resulted from the previous pregnancy.

\section{Conclusion}

The prevalence of anemia in the study area was low and HIV status, intestinal parasite, and inter-pregnancy gap were variables significantly associated.

\section{Recommendation}

Although the condition appears mild as per the WHO criterion awareness creation on prevention of HIV, 
personal hygiene and environmental sanitation to control intestinal parasite infection, and use of contraceptives to widen the inter-pregnancy gap are important to further prevent pregnancy-related anemia. Since the present investigation was conducted on a relatively smaller small sample size, studies using a larger sample size are needed to better understand the scale of anemia among pregnant women in the study area.

\section{Limitation}

Smaller sample size and the nature of cross-sectional study which does not show cause and effect relationship.

\author{
Abbreviations \\ IPIs: intestinal parasitic infections; WHO: World Health Organization; Hgb: \\ hemoglobin; EDHS: Ethiopian Demographic Health Survey; HIV: human \\ immunodeficiency virus.
}

\section{Authors' contributions}

AK, HG, GT have taken a principal role in the conception of ideas, developing methodologies and writing the article. FA and YT involved in data collection, analysis, and interpretation of the data. All authors read and approved the final manuscript.

\section{Author details}

${ }^{1}$ School of Nursing, College of Health Sciences and Comprehensive Specialized Hospital, Aksum University, Aksum, Ethiopia. ${ }^{2}$ Students Clinic, Aksum University, Shire Campus, Shire, Ethiopia.

\section{Acknowledgements}

We would like to thank all study participants and data collectors for their contribution to the success of our work.

\section{Competing interests}

This manuscript maintains no competing financial interest declaration from any person or organization, or non-financial competing interests such as political, personal, religious, ideological, academic, intellectual, commercial or any other.

\section{Availability of data and materials}

The data sets used and analyzed during the current study available from the corresponding author on reasonable request.

\section{Consent to publish}

Not applicable.

\section{Ethics approval and consent to participate}

Ethical clearance was secured from the Aksum University, College of Health Science research review committee. Respondents were well informed about the purpose of the study, and information was collected after full oral and written consent from participants aged 18 years and more, but age less than 18 years from the guardian. Information was recorded anonymously and confidentially, and beneficence was assured throughout the study period.

\section{Funding}

There is no funding for this research. All cost of data collection and analysis were covered by the authors.

\section{Publisher's Note}

Springer Nature remains neutral with regard to jurisdictional claims in published maps and institutional affiliations.
Received: 13 July 2018 Accepted: 10 August 2018

Published online: 17 August 2018

\section{References}

1. WHO. Serum and red blood cell folate concentrations for assessing folate status in populations. Vitamin and mineral nutrition information system. Geneva; 2015. http://apps.who.int/iris/bitstream/10665/162114/1/WHO NMH_NHD_EPG_15.01.pdf?ua=1. Accessed 12 Sept 2015.

2. CDC, WFP. A manual: measuring and interpreting malnutrition and mortality. Atlanta: Center for Disease Control and Prevention and World Food Programme; 2005.

3. Buseri Fl, Uko EK, et al. Prevalence and risk factor among pregnant women in Nigeria. Open Hematol J. 2008;2:14-9.

4. Abel G, Afework M. Prevalence of anemia and associated factor among pregnant women in northwestern Zone of Tigray, Northern Ethiopia: across-sectional study. J Nutr Metab. 2015; 7. Article ID 165430.

5. Gidey G, Hailu B, Nigus K, Hailu T, Gerensea H. Timing of first focused antenatal care booking and associated factors among pregnant mothers who attend antenatal care in Central Zone, Tigray, Ethiopia. BMC Res Notes. 2017;10(1):608.

6. Kebede A, Molla B, Gerensea H. Assessment of risky sexual behavior and practice among Aksum University students, Shire Campus, Shire Town, Tigray, Ethiopia, 2017. BMC Res Notes. 2018;11:88. https://doi. org/10.1186/s13104-018-3199-7.

7. Gerensea H, Kebede A, Baraki Z, Berihu H, Zeru T, Birhane E, Hintsa S, Siyum H, Kahsay G, Gidey G, Teklay G. Consistency of Integrated Management of Newborn and Childhood IIIness (IMNCI) in Shire Governmental Health Institution in 2017. BMC Res Notes. 2018;11(1):476.

8. Gerensea $\mathrm{H}$, Teklay H. Trend of hypertension morbidity and mortality in Tigray Region from 2011 to 2015, Tigray, Ethiopia. BMC Res Notes. 2018;11(1):375.

9. Mariye T, Tasew H, Teklay G, Gerensea H, Daba W. Magnitude of diabetes self-care practice and associated factors among type two adult diabetic patients following at public Hospitals in central zone, Tigray Region, Ethiopia, 2017. BMC Res Notes. 2018;11(1):380.

10. Seid A, Gerensea H, Tarko S, Zenebe Y, Mezemir R. Prevalence and determinants of erectile dysfunction among diabetic patients attending in hospitals of central and northwestern zone of Tigray, northern Ethiopia: a cross-sectional study. BMC Endocr Disord. 2017;17(1):16.

11. Birhane E, Kidanu K, Kassa M, Gerezgiher D, Tsegay L, Weldu B, Kidane G, Gerensea H. Lifespan and associated factors of peripheral intravenous Cannula among infants admitted in public hospitals of Mekelle City, Tigray, Ethiopia, 2016. BMC Nurs. 2017;16(1):33.

12. Baraki Z, Girmay F, Kidanu K, Gerensea H, Gezehgne D, Teklay H. A cross sectional study on nursing process implementation and associated factors among nurses working in selected hospitals of Central and Northwest zones, Tigray Region, Ethiopia. BMC Nurs. 2017;16(1):54.

13. Wondu T, Bijlsma M. The hidden hunger": understanding the burden of anemia and its determinants among pregnant and non-pregnant women in Ethiopia. Afric J Food Agri Nutr Dev. 2012;12:7.

14. Abraham A, Yesuf ME, Wassie MM. Prevalence and associated factors of anemia among pregnant women of Mekelle town: a cross-sectional study. BMC Res Notes. 2014;7:888.

15. Alem M, Enawgaw B, Gelaw A, Kena T, Seid M, Olkeba Y. Prevalence of anemia and associated risk factors among pregnant women attending antenatal care in Azezo health center Gondar town, northwest Ethiopia. J Interdiscipl Histopathol. 2013;1(3):137-44.

16. Getachew M, Yehualaw D, Taffess K, Getachew Y. Anemia and associated risk factors among pregnant women in Gilgel Gibe dam area, southwest Ethiopia. Parasit Vectors. 2012;5:296.

17. Kefiyalew F, Zemene E, Asres Y, Gedefaw L. Anemia among pregnant women in Southeast Ethiopia: prevalence, severity and associated risk Factors. BMC Res Notes. 2014;7:771

18. Mirzaie F, Eftekhari N, Goldozeian S, Mahdavinia J. Prevalence of anemia risk factors in pregnant women in Kerman, Iran. Iran J Rep Med. 2010:8(2):66-9.

19. Obse N, Mossie A, Gobena T. Magnitude of anemia and associated risk factors among pregnant women attending antenatal care in Shalla 
Woreda, West Arsi Zone, Oromia Region, Ethiopia. Ethiop J Health Sci. 2013;23(2):165-72.

20. Ababiya T, Gabriel T. Prevalence of anemia among pregnant women in Ethiopia and its management; a review. Inter Res J Pharm. 2014:5(10):737-45.

21. Antelman G, Msamanga GI, Spiegelman D, Urassa NJE, Narh R, Hunter JD, Fawzi WW. Prevalence of anemia among pregnant women attending antenatal care at Selam Health Center. Addis Ababa, Ethiopia; 2000, pp. $1-20$.

22. Gedefaw L, Ayele A, Asres Y, Mossie A. Anemia and associated risk factors among pregnant women attending antenatal care clinic in Wolayita Sodo town, southern Ethiopia. Ethiop J Health Sci. 2015;25(2):155-62.
Ready to submit your research? Choose BMC and benefit from:

- fast, convenient online submission

- thorough peer review by experienced researchers in your field

- rapid publication on acceptance

- support for research data, including large and complex data types

- gold Open Access which fosters wider collaboration and increased citations

- maximum visibility for your research: over 100M website views per year

At BMC, research is always in progress.

Learn more biomedcentral.com/submissions 